\title{
New structural seismic protection for high-rise building structures
}

\author{
Azer A. Kasimzade', Obaidullah Abrar², Gencay Atmaca ${ }^{3}$, Mehmet Kuruoglu ${ }^{4}$ \\ ${ }^{1,2}$ Department of Civil Engineering, Ondokuz Mayis University, Samsun, 55100, Turkey \\ ${ }^{3}$ Provincial Directorate of Disaster and Emergency, Samsun, 55200, Turkey \\ ${ }^{4}$ Department of Civil Engineering, Dokuz Eylul University, Izmir, 35160, Turkey \\ ${ }^{1}$ Corresponding author \\ E-mail: ${ }^{1}$ azer@omu.edu.tr, ${ }^{2}$ obaidullah.abrar@gmail.com, ${ }^{3}$ gencayatmaca@hotmail.com, \\ ${ }^{4}$ mehmet.kuruoglu@deu.edu.tr
}

Received 21 April 2019; received in revised form 6 November 2019; accepted 13 November 2019 DOI https://doi.org/10.21595/jve.2019.20741

Check for updates

Copyright (C) 2020 Azer A. Kasimzade, et al. This is an open access article distributed under the Creative Commons Attribution License, which permits unrestricted use, distribution, and reproduction in any medium, provided the original work is properly cited.

\begin{abstract}
Presented Structural Seismic Isolation Method (SSIM) aims to provide high safety for Highly Reliable Structures (HRS) against strong earthquakes including near-fault and long-period ground motions. The examined structure is converted to Structural Seismic Isolation System (SSIS) by the SSIM method which exhibited inverse pendulum behaviour. For this purpose, structure foot base and foundation contact surfaces have been designed as any curved surfaces (spherical, elliptical, etc.) depending on the earthquake-soil-superstructure parameters and this contact surfaces have been separated by elastomeric (lead core rubber or laminated rubber bearings) seismic isolation devices. It would allow the structure foot base to turn around gyration centre through rubber bearing contact and maintains similar behaviour to the super-structure. SSIS system provides the possibility of keeping the natural-period of the structure in a larger interval, which is greater than the predominant-period of the majority of possible earthquakes (including near-fault pulse) using currently existing conventional elastomeric isolators with up to 4 second period. Thus, the structure can sustain its serviceability after strong and long-period earthquakes. In this study SSIS system's performance is presented for high-rise building structures, for this aim, the finite element model of the building (Bg) structure with SSIS system (SSIS-Bg) has been prepared and the nonlinear dynamic analysis of the model has been conducted using strong and long-period ground motions. Results indicate that the base and top accelerations, base shear and base moment responses of the SSIS-Bg structure is $23.21 \%, 75.47 \%$ and $85.74 \%$ in average lower than the Conventional Application Method of Seismic Base Isolation Devices for Building (CAMSBID-Bg) structures respectively and it is not prone to resonant vibrations under long-period earthquakes related with the excessive deformation in the isolation layers in case of using CAMSBID-Bg structures. It should be noted that in this study with the presented SSIM method and SSIS system, it is aimed to protect only the Highly Reliable Structures(HRS) from the effects of strong and long-period ground motions and these structures (HRS) are classified as follows: 1) Nuclear Containment Structures; 2) High-rise buildings that contain information, operating systems, sensitive instruments, communication systems, routing systems, bank operating systems, databases, management systems and other similar facilities that are linked to the security and economy of a country; 3 ) High-rise hospitals etc.
\end{abstract}

Keywords: aseismic base isolation, SSIM method and SSIS system, earthquake resistant structures, nonlinear FEM, long-period earthquake.

\section{Introduction}

Near-fault ground motions (e. g. 1978 Tabas, 1995 Kobe, 1999 Chi-Chi) caused severe damages to buildings and bridges and resulted in serious causalities [1,2]. The pulse period of near-fault earthquakes ranges between 1.4-7 secs for the earthquakes with a magnitude of 6 to 7.6 [3]. The pulse period ranges for all of the near-fault earthquakes records used in this study are between $0.5-12.9$ secs. Characteristics of strong earthquake ground motion in the period range 
from 1 to 15 seconds was classified [4], thus, it can generate long-period ground motions which can be harmful to long-period structures [4, 5]. On the other hand, far-field long-period earthquakes (e. g. 1985 Mexico City, 2010 Darfield, 2011 Tohoku) can cause the same amount of damage for high-rise structures as well $[6,7]$. Usage of seismic isolation systems for the purpose of protection of structures against strong earthquakes became widespread and considered as an effective method for seismic protection of structures $[8,9]$. Various types of seismic isolation methods such as elastomeric, friction pendulum etc. have been developed and implemented in practice. It is obvious that seismic isolation provides better safety for structures during strong earthquakes. In short, as a result of using the Conventional Application Method of the Seismic Base Isolation Devices for Building (CAMSBID-Bg) structures [8, 9], superstructure's dominant period will be shifted to the seismic base isolation device's dominant period, which is the about 2-4 seconds in currently available devices. Therefore, the accelerations in the superstructure are significantly reduced compared to the earthquake acceleration. Several reports indicate the vulnerability of base-isolated structures against near-fault pulse and long-period earthquakes (with a dominant period of more than 2-4 seconds). For instance, during the 2011 Tohoku, Japan earthquake seismic isolation level of buildings suffered serious damages due to large displacements $[10,11]$. In other words, in the CAMSBID-Bg structures, the resonance of the upper structure is inevitable under long-period (more than 2-4 second) earthquake effects and this leads to structural damage and halts its service.

As seen from the references protection of the structures from the effects of strong and long-period ground motions has not been solved by the conventional application method of the seismic base isolation devices (CAMSBID) method [8,9] and the reasons (A, B) are summarized below:

A) The vibration period of Lead Rubber Bearing (LRB) and Lead Core Rubber Bearing (LCRB) seismic base insulation devices are currently limited between the range of 2-4 seconds. The mentioned types of seismic base isolation devices are added to the structures by the CAMSBID method and their dominant period is shifted to the range of 2-4 seconds, thereby mitigating the earthquake effect. However, these structures remain unprotected by resonance in the event of the effects of long-period (more than 4 seconds) components of ground motion.

B) Because the Friction Pendulum Bearing (FPB) type seismic isolator carries the building load to the small area pendulum bearing on the friction surface of the device and it causes following three disadvantages: This device cannot work immediately by creating a permanent deformation on the friction surface of the device during the waiting period until the devastating earthquake occurs (1). In structures with high gravitation loads, the risk of tearing of the plate under the pendulum support is very high (2). The vibration period of FPB seismic base isolation devices is currently in the range of 2-6 seconds in case of ideal zero friction (3). Due to these known shortcomings in the implementation of these devices, the effective usage of the FPB devices is limited.

According to the literature, there are several studies on enhancing the performance of seismic base-isolated structures against near-fault and far-source long-period earthquakes. Sliding seismic isolation with controllable stiffness method was proposed and studied by Lu et al. [12]. Hosseini et al. carried research on the feasibility of the application of orthogonal pairs of rollers on concave beds as a seismic isolation system for the protection of mid-rise structures [13]. Ismail (2015) proposed a new seismic isolation device with a self-stopping mechanism to dissipate the harmful effect of near-fault earthquakes [14]. Another study suggests using of wave generator in the boundary of structure to reduce the amplitude of ground vibrations [15]. Seismic protection of medium-rise RC (reinforced concrete) structure using elastomeric and sliding seismic isolators against the harmful effect of the near-fault earthquake was studied by Fabio et al. [16]. These studies [12-16] include solutions for specific situations and are difficult to generalize like conventional seismic isolation (CAMSBID) methods $[8,9]$.

Kasimzade et al. [17-21] proposed and developed new Structural Seismic Isolation Method (SSIM) for protection of structures against strong and long-period ground motions and aims to 
eliminate the limitation and vulnerability of the conventional elastomeric (lead rubber or laminated rubber bearing) base-isolated structures for same excitations [22]. On the bases of this method, the present structure is converted to a Structural Seismic Isolation System (SSIS) by the SSIM method, which exhibited inverse pendulum behaviour. SSIS system provides the possibility of keeping the natural-period of the structure in a larger interval, which is greater than the predominant-period of the majority of possible earthquakes (including near-fault pulse) using currently existing conventional elastomeric isolators with up to 4 second period and it is not caused resonant vibrations under long-period earthquakes.

The related patents "Anti-earthquakes structure insulating kinetic energy of earthquake from buildings" [23], "Earthquake-proof object support device" [24], "Rocking-type seismic isolation base for protecting structure against earthquake [25], "Friction Pendulum Bearing" [26], "Anti Seismic Support" [27], "An Earthquake-Proof Building” [28], "The double-spherical friction single pendulum support saddle" [29], "Spheroidal joint for column support in Tuned Mass Damper System" [30], "Assembly Type Building-Foundation And Construction" [31], "Base Isolation Supporting Device" [32], "Circle-egg thin-shell frame shake-type earthquake-waveresistant architectural structure" [33], "Ovum circle shell frame shaking type ripples building structure of antiseismicing" [34] and "Sliding Bearing For Supporting Civil Or Structural Engineering Works" [35] on the subject of the seismic protection of the structures were examined and it was found that the solution of the mentioned subject with SSIM method was a first and original and a patent application was made on the subject [21].

In this study, the dynamic performance of SSIM method application for high-rise steel SSIS system building structure (SSIS-Bg) was presented in comparison with the conventional application method of the seismic base isolation devices for building structures (CAMSBID-Bg) and fixed base building structures (FB-Bg) using finite element simulation.

\subsection{Fundamentals and advantages of SSIM method}

As mentioned, Structural Seismic Isolation Method (SSIM) aims to provide high safety for Highly Reliable Structures (HRS) against strong earthquakes including near-fault and long-period ground motions. On the bases of this method, the present structure is converted to a Structural Seismic Isolation System (SSIS) by the SSIM method, which exhibited inverse pendulum behaviour. For this purpose, structure foot base (Fig. 1(a), part 2) and foundation contact surfaces (Fig. 1(a), part 4) can be designed as any curved surfaces (spherical, elliptical, etc) depending on the earthquake-soil-superstructure parameters and this contact surfaces are separated by elastomeric (lead core rubber or laminated rubber bearings) seismic isolation devices (Fig. 1(a), part 3). It would allow the structure foot base to turn around gyration centre through rubber bearing contact and maintains similar behaviour to the superstructure (Fig. 1(a), part 1). SSIS system provides the possibility of keeping the natural-period of the structure in a larger interval, which is greater than the predominant-period of the majority of possible earthquakes (including near-fault pulse) using currently existing conventional elastomeric isolators with up to 4 second period. In the case of using the CAMSBID-Bg structure (Fig. 1(c)), superstructure's vibration dominant period will be approximately equal to the elastomeric isolator's dominant period (2-4 second). Therefore, CAMSBID-Bg structure is prone to resonant vibrations under long-period earthquakes related to the excessive deformation in the isolation layers. Consequently, CAMSBID-Bg structures are vulnerable under near-fault and long-period ground motions. Due to this problem, the conventional application of the currently available seismic base isolation elastomeric devices is limited. In addition, as the SSIS system provides the opportunity of controlled rotation to the superstructure, less bending moment and shear force will be formed in the superstructure base, in comparison with CAMSBID-Bg structures.

Major advantages of SSIS system obtained by the SSIM method over previously studied methods [12-16] and CAMSBID method $[8,9]$ can be noted as follows:

- SSIS system is applicable for highly reliable structures including high-rise buildings while 
the majority of mentioned studies are focused on low-rise or medium-rise structures.

- Some of the mentioned seismic isolation methods require extra energy to function which may be inconvenient in some cases. On the other hand, the SSIS system is a totally passive seismic isolation which does not require any extra energy for functioning.

- The usage of friction pendulum isolator for the purpose of seismic isolation could be problematic due to stick-slip and non-uniform pressure distribution of the pendulum on steel plate, while the SSIS system uses elastomeric isolators.

- SSIS system is more reliable than CAMSBID-Bg systems under the effect of long-period and near-fault earthquakes due to the fact that the period of seismic isolators used in CAMSBID-Bg structure is between 2-4 seconds. While SSIS system's period is much higher thanks to turn-around gyration centre and it does not cause resonant vibrations.

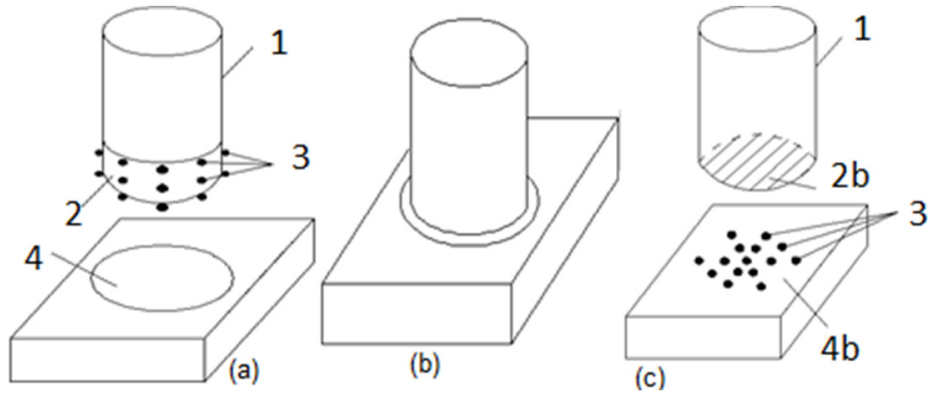

Fig. 1. Schematic illustration of a) the SSIS system obtained by SSIM method and b) completed SSIS-Bg structure and c) CAMSBID-Bg structure: 1 - superstructure, 2 - curved surface superstructure foot base, 3 - elastomeric seismic isolation devices, 4 - foundation contact curved surface, $2 \mathrm{~b}$ - plane surface CAMSBID-Bg superstructure foot base,

$4 \mathrm{~b}$ - Foundation contact plane surface of CAMSBID-Bg structure [21]

The governing equation and the mathematical model of the SSIS system with the spherical structure foot base and foundation contact surfaces (Fig. 2) have been presented as following [19]:

$[m]\{\ddot{u}\}+[c]\{\dot{u}\}+[k]\{u\}=\left\{F_{\ddot{u}}\right\}$,
$\ddot{\varphi} C_{2}+\dot{\varphi} C_{1}-\varphi C_{01} g+\rho_{2} F_{k b}(\varphi)=\ddot{u}_{g} C_{02}$.

With:

$F_{k b}=\alpha k_{b} u_{b}+(1-\alpha) F_{y} Z$,

$F_{y}=Q+\alpha k_{b} u_{y}$

$\dot{Z}=\left[a \dot{u}_{b}-\beta\left|\dot{u}_{b}\right| Z|Z|^{n-1}-\gamma \dot{u}_{b}|Z|^{n}\right] u_{y}^{-1}$,

$C_{1}=\rho_{2}^{2}\left(c_{d}+c_{b}\right)$,

where $[m],[c],[k]$ are mass, Rayleigh damping and stiffness matrix of the superstructure respectively and it is composed by FEM [35], $u$ is the relative displacement vector of the deformed states of the superstructure. $\dot{u}$ and $\ddot{u}$ are the velocity and acceleration vector respectively. $F_{\ddot{u} g}$ stands for seismic force:

$\left\{F_{\ddot{u}_{g}}\right\}=\left\{\begin{array}{c}m_{1}\left(\ddot{u}_{g}-\ddot{u}_{01}\right) \\ m_{2}\left(\ddot{u}_{g}-\ddot{u}_{02}\right) \\ \ldots \\ m_{i}\left(\ddot{u}_{g}-\ddot{u}_{01}\right) \\ \ldots \\ m_{n}\left(\ddot{u}_{g}-\ddot{u}_{0 n}\right)\end{array}\right\}, \quad\left\{\ddot{u}_{0}\right\}=\left\{\begin{array}{c}\ddot{u}_{01} \\ \ddot{u}_{02} \\ \ldots \\ \ddot{u}_{0 i} \\ \ldots \\ \ddot{u}_{0 n}\end{array}\right\}=\left\{\begin{array}{c}h_{1} \\ h_{2} \\ \ldots \\ h_{i} \\ \ldots \\ h_{n}\end{array}\right\} \ddot{\varphi}, \quad\{u\}=\left\{\begin{array}{c}u_{1} \\ u_{2} \\ \ldots \\ u_{i} \\ \ldots \\ u_{n}\end{array}\right\}$, 
with:

$u_{0 i}=\varphi h_{0 i}, \quad \ddot{u}_{0 i}=\ddot{\varphi} h_{i}, \quad u_{b}=\varphi \rho_{2}$,

where, $\varphi$ represents the absolute rigid structure's rotation angle around the gyration centre, $\ddot{u}_{g}$ is the ground motion excitation; $F_{c 0}=c_{b} \rho_{2} \dot{\varphi}$ is total damping and $F_{k b}$ total stiffness forces of seismic isolator deployed in SSIS system which possess $c_{b}$ (total damping-coefficient) and spherical radius $\left(\rho_{2}\right) . F_{c, e q}=c_{d} \rho_{2} \dot{\varphi}$ represents the sum of external dampers' equal damping force which contains the $c_{d}$ (damping coefficient). $\varphi$ is the solution of the Eq. (2):

$$
\begin{aligned}
C_{2} & =2\left(\sum_{i=1 \ldots n} m_{i} h_{i}{ }^{2}+\sum_{j=1 \ldots m} m_{0 j} h_{0 j}^{2}\right), \\
C_{01} & =\sum_{i=1 \ldots n} m_{i} h_{i}-\sum_{j=1 \ldots m} m_{0 j} h_{0 j} \\
C_{02} & =\sum_{i=1 \ldots n}^{j} m_{i} h_{i}-\sum_{j=1 \ldots m} m_{0 j} h_{0 j}
\end{aligned}
$$

where $h_{i}(i=1, n)$ is the $z$ distance of the superstructure's $i$-th mass $m_{i}$ from the gyration centre, $m_{0 j}, h_{0 j},(j=1, m)$ are similar parameters for the underground part of the SSIS system.

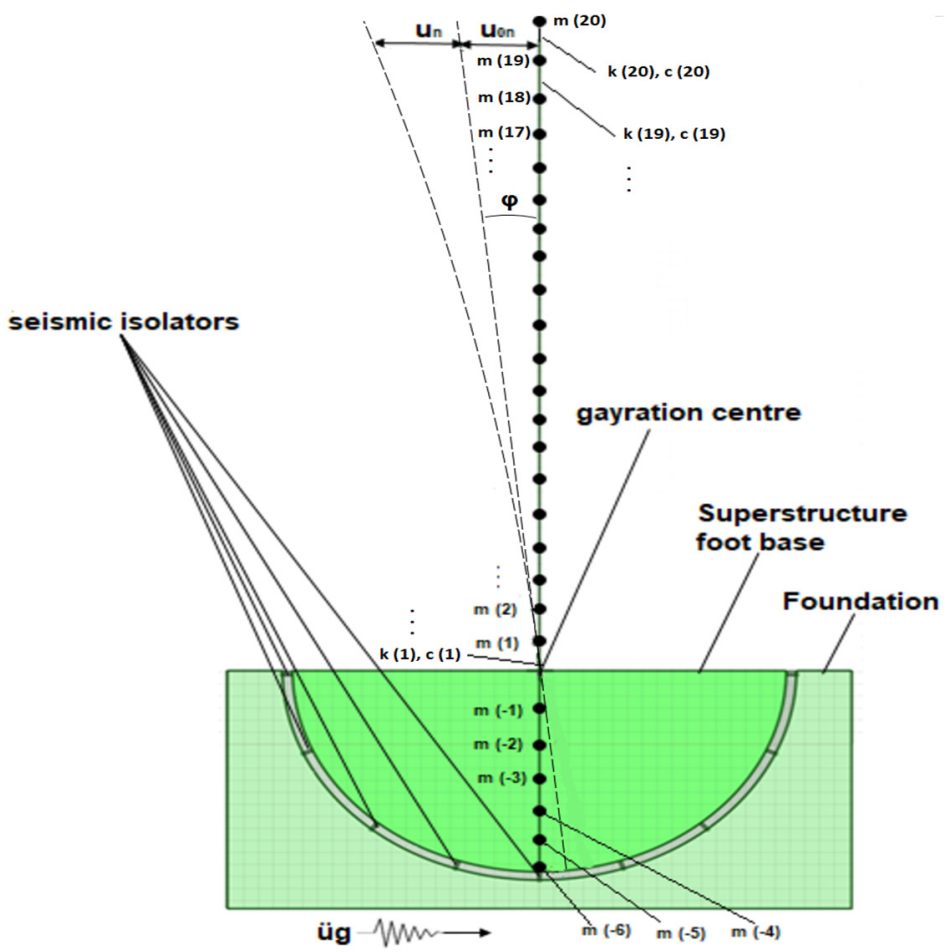

Fig. 2. General working mechanism schema of the SSIS-Bg system

The lateral displacement of superstructure's base is indicated by $\left(u_{b}\right)$ which correlates to the contact surface of the foundation. $u_{y}$ (yield displacement), $k_{b}$ (total stiffness) of the isolators, $\alpha$ (post to pre-yielding stiffness ratio commonly taken as; $\alpha=0.1$ ). The rations $d_{r}=u_{y b 2} / u_{y}=$ 9.98 and $f_{r}=F_{y b 2} / F_{y}=2.01$ respectively as described in Fig. 3. The parameter $\dot{Z}$ refers to dimensionless hysteresis displacement component satisfies the nonlinear first-order [37, 38] 
differential Eq. (5), $F_{y}$ and $Q$ refer to yield and characteristic strengths of the seismic isolator respectively. By defining the $F_{0}$ parameter as presented in Eq. (12) with regard to the total weight of the structure $W$ the yield strength of the seismic isolator can be normalized:

$F_{0}=\frac{F_{y}}{W}$

In some references normalized stiffness has been expressed as follows:

$$
\begin{aligned}
& f_{0}=\frac{Q}{W} . \\
& W=g m_{t}, \\
& m_{t}=m_{b}+\sum_{i=1}^{n} m_{i},
\end{aligned}
$$

where $m_{i}, m_{b}$, and $m_{t}$ are the mass of the storey, base slab and total mass of the building respectively.

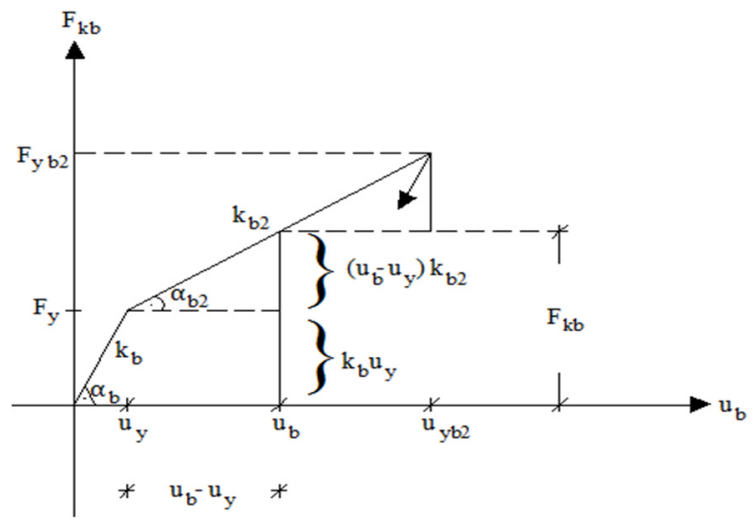

Fig. 3. Illustration of the hysteresis loop of the LCRB isolator and its geometric rations [19]

In Eq. (5) $\beta, \alpha, n$ and $\gamma$ are dimensionless parameters and affects the shape of the hysteresis loop, the value of these parameters are predicted through experiments. Here, the value of above mentioned parameters are taken as: $n=2 ; \alpha=1$ and $(\beta+\gamma) / a=1$. The model of Eq. (5) decreases to a viscoplasticity model, in Eq. (5) $u_{y}$ refers to yield displacement. The base and top absolute displacement $\left(u_{b, a b s}, u_{n, a b s}\right)$ and acceleration $\left(\ddot{u}_{b, a b s}, \ddot{u}_{n, a b s}\right)$ behaviour of SSIS-Bg structure are described via Eq. (16):

$u_{n, a b s}=\left|-u_{n}-u_{0 n}\right|=u_{t o p, a b s}, \quad \ddot{u}_{n, a b s}=\left|-\ddot{u}_{g}-\ddot{u}_{n}-\ddot{u}_{0 n}\right|=u_{t o p, a b s}$, $u_{b, a b s}=\left|-u_{g}+u_{b}\right|, \quad \ddot{u}_{b, a b s}=\left|-\ddot{u}_{g}+\ddot{u}_{b}\right|$,

were, $u_{b}, u_{n}$ and $\ddot{u}_{b}, u_{0 n}$ are the base and top relative displacement and acceleration; $u_{0 n}, \ddot{u}_{0 n}$ are the top relative displacement and acceleration of the SSIS-Bg structure as a rigid body.

Pre-sizing and assessment of SSIS-Bg structure have been conducted by MATLAB and Simulink programming tools using presented governing equations by Kasimzade et al. [19] in the following section. 


\subsection{Assessment of the SSIS-Bg structure according to the basic demands of the SSIM method}

A numerical verification of the SSIS-Bg structure is presented with an example of 26 storey steel framed structure. For comparability of the SSIS-Bg, FB-Bg and CAMSBID-Bg structures, its storey height, column axes ranges were accepted same respectively with an equal total mass of $3.04894 \mathrm{E}+7 \mathrm{~kg}$ as presented in Table 3. Pre-sizing SSIS-Bg (26-storey, $104 \mathrm{~m}$ ), CAMSBID-Bg (24-storey, $96 \mathrm{~m}$ ) and FB-Bg (24-storey, $96 \mathrm{~m}$ ) steel superstructures are designed so that the maximum story angle is lower than 1/200. The steel grade SN-490 (with $357.0 \mathrm{MPa}$ yield strength) for superstructure and reinforced concrete for the base part is used as material for members (Table 1). Total floor load (per meter square) containing the dead load of the columns and beams is $7840.0 \mathrm{~N} / \mathrm{m}^{2}$. Storey height, column axes ranges are accepted $4 \mathrm{~m}, 8 \mathrm{~m}$ respectively. Pre-sizing results for beams and columns were presented in Table 2. The floor mass distribution for FB-Bg, CAMSBID-Bg and SSIS-Bg structures are presented in Table 3.

The total superstructure mass $\left(M_{\text {total superstore }}\right)$ of CAMSBID-Bg and FB-Bg is presented according to the total mass of SSIS-Bg as following:

$M_{\text {total superstore }(F B-B g \& C A M S B I D-B g)}=M_{\text {total }(S S I S-B g)}-M_{\text {Isolation Layer(CAMSBID-Bg) }}$, $(3.17750 E+7-0.12858 E+7) k g=3.04894 E+7 k g$.

Table 1. Material properties of steel for superstructure and reinforced concrete for the base part of SSIS-Bg

\begin{tabular}{|c|c|c|}
\hline Material properties & Steel & reinforced concrete \\
\hline Elasticity modulus $\left[\mathrm{N} / \mathrm{m}^{2}\right]$ & $2.05 \mathrm{E}+11$ & $3.80 \mathrm{E}+10$ \\
\hline Density $\left[\mathrm{kg} / \mathrm{m}^{3}\right]$ & 7860 & 2400 \\
\hline Poisson's ratio & 0.3 & 0.2 \\
\hline
\end{tabular}

Table 2. The dimension of the storey column and beams

\begin{tabular}{|c|c|c|c|c|c|c|}
\hline \multirow{2}{*}{ Stories } & \multicolumn{2}{|c|}{ Column (box-section) } & \multicolumn{4}{|c|}{ Beam (I-section) } \\
\cline { 2 - 7 } & Width $x$ breadth [m] & Thickness $[\mathrm{m}]$ & $H^{*}[\mathrm{~m}]$ & $W[\mathrm{~m}]$ & $F T[\mathrm{~m}]$ & $W T[\mathrm{~m}]$ \\
\hline $1-10$ th & $0.8 \times 0.8$ & 0.02 & 0.8 & 0.3 & 0.03 & 0.015 \\
\hline $11-20$ th & $0.65 \times 0.65$ & 0.016 & 0.8 & 0.3 & 0.03 & 0.015 \\
\hline 21-26th & $0.47 \times 0.47$ & 0.012 & 0.8 & 0.3 & 0.03 & 0.015 \\
\hline$* H$ (Height), $W$ (Flange width), $F T$ (Flange thickness and $W T$ (Web thickness) \\
\hline
\end{tabular}

Table 3. The distribution of the floor masses for SSIS-Bg, CAMSBID-Bg and FB-Bg structures

\begin{tabular}{|c|c|c|c|c|c|c|}
\hline & \multicolumn{2}{|c|}{ SSIS-Bg } & \multicolumn{2}{|c|}{ CAMSBID-Bg } & \multicolumn{2}{|c|}{ FB-Bg } \\
\hline \multirow{6}{*}{ 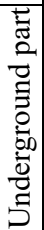 } & -6th floor (isol. lay.) & $1.7926 \mathrm{E}+06$ & Isolation layer & $1.28580 \mathrm{E}+6$ & 1st floor & $1.33118 \mathrm{E}+6$ \\
\hline & -5 th floor & $6.3729 \mathrm{E}+05$ & 1st floor & $1.33118 \mathrm{E}+6$ & 2nd floor & $1.33118 \mathrm{E}+6$ \\
\hline & -4 th floor & $8.5559 \mathrm{E}+05$ & 2nd floor & $1.33118 \mathrm{E}+6$ & 3rd floor & $1.33118 \mathrm{E}+6$ \\
\hline & -3 rd floor & $9.9259 \mathrm{E}+05$ & 3rd floor & $1.33118 \mathrm{E}+6$ & 4th floor & $1.33118 \mathrm{E}+6$ \\
\hline & -2 nd floor & $1.0798 \mathrm{E}+06$ & 4th floor & $1.33118 \mathrm{E}+6$ & 5th floor & $1.33118 \mathrm{E}+6$ \\
\hline & -1 st floor & $1.1288 \mathrm{E}+06$ & 5th floor & $1.33118 \mathrm{E}+6$ & 6th floor & $1.33118 \mathrm{E}+6$ \\
\hline \multirow{6}{*}{ 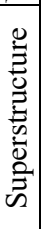 } & 1-3rd floor & $1.33827 \mathrm{E}+06$ & 6-7th floor & $1.33118 \mathrm{E}+6$ & 7th floor & $1.33118 \mathrm{E}+6$ \\
\hline & 4 th floor & $1.31392 \mathrm{E}+06$ & 8th floor & $1.30683 \mathrm{E}+6$ & 8th floor & $1.30683 \mathrm{E}+6$ \\
\hline & 5-13th floor & $1.28957 \mathrm{E}+06$ & 9-18th floor & $1.28248 \mathrm{E}+6$ & 9-18th floor & $1.28248 \mathrm{E}+6$ \\
\hline & 14th floor & $1.28410 \mathrm{E}+06$ & 19th floor & $1.27701 \mathrm{E}+6$ & 19th floor & $1.27701 \mathrm{E}+6$ \\
\hline & 15-19th floor & $1.27863 \mathrm{E}+06$ & 20-23th floor & $1.27154 \mathrm{E}+6$ & 20-23th floor & $1.27154 \mathrm{E}+6$ \\
\hline & Top floor & $6.76301 \mathrm{E}+5$ & Top floor & $6.76342 \mathrm{E}+5$ & Top floor & $6.76342 \mathrm{E}+5$ \\
\hline \multicolumn{2}{|r|}{ Total superstructure } & $2.53450 \mathrm{E}+7$ & Total superstructure & $3.04894 \mathrm{E}+7$ & \multirow{2}{*}{\multicolumn{2}{|c|}{ Total structure $3.04894 \mathrm{E}+7$}} \\
\hline & Total structure & $3.17750 \mathrm{E}+7$ & Total structure & $3.17752 \mathrm{E}+7$ & & \\
\hline
\end{tabular}

Assuming that the predominant period of the earthquakes in the area where FB-Bg, CAMSBID-Bg and SSIS-Bg structures will be built is about $11 \mathrm{~s}$. The required total elastomeric 
isolator horizontal stiffness for the first approximation for the SSIS system is described in accordance with Eq. (2), in case of free vibration as $k_{b}=8.2455 \mathrm{E}+7 \mathrm{~N} / \mathrm{m}$. Other parameters of the elastomeric isolator such as period, damping coefficient and damping ratio were defined as $T_{b}=4 \mathrm{~s}, c_{b}=1.5182 \mathrm{E}+7 \mathrm{Ns} / \mathrm{m}^{2}, \xi_{b}=0.15$ respectively.

Based on above SSIS-Bg structure's parameters and using governing equations for SSIS system from the previous section, SSIS-Bg structure's performance was preliminary assessed to Kobe 1995 Earthquake $X$-direction acceleration excitation and base acceleration response were presented in Fig. 4.

As seen, the acceleration in the SSIS-Bg structure's base significantly (about four times) was reduced. Based on preliminary design parameters and assessments results presented in this section, detailed finite element modelling of the SSIS-Bg structure comparing with FB-Bg, CAMSBID-Bg structures were presented in the following section.

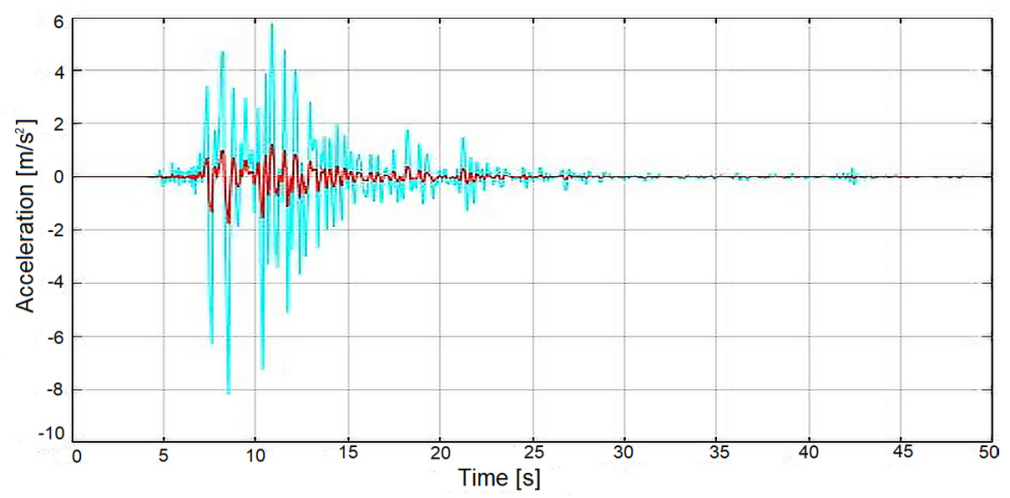

Fig. 4. Base acceleration responses of SSIS-Bg structure (red) in $X$-direction under the effect of the Kobe earthquake (cyan)

\section{Finite element structural model of steel building with SSIS system}

Finite element modelling of the steel building with the SSIS system has been prepared in the LS-DYNA software [39], tetrahedron solid, beam and isolator link finite elements were used (Fig. 5). The material properties, section properties, and mass distribution of the finite elements are in accordance with Tables 1, 2, 3 respectively. Isolator links (discrete beam isolator) finite element's parameters definition, pre-sizing and finalization design were exhibited in the following sections. The isolator links are modelled based on bi-directional coupled plasticity theory, the hysteretic behaviour was proposed by (Wen 1976) [25].

\subsection{Preliminary design of the seismic elastomeric isolators}

The preliminary dimension and analytical parameters of the seismic isolators are calculated based on ASCE 7-16 [40] and ASCE 41-13 [41] codes. Yield force $\left(F_{v}\right)$, yield displacement $\left(u_{y}\right)$, damping ratio and the vertical stiffness $\left(K_{v}\right)$ are the necessary analytical parameters for finite element modelling of the seismic isolators. Minimum horizontal stiffness and the design displacement of the isolator are calculated using Eq. (17) and (18) respectively:

$$
\begin{aligned}
& K_{D \min }=\frac{4 \pi^{2} W}{T_{D}^{2} g}, \\
& D_{D}=\frac{g S_{D 1} T_{D}}{4 \pi^{2} B_{D}}
\end{aligned}
$$

where $W$ stands for the total weight on a single bearing, $T_{D}$ for design period (here $T_{D}=4 \mathrm{~s}$ ), $B_{D}$ 
for damping coefficient, $g$ for gravity, $S_{D 1}$ for spectral coefficient. The cross-section area of rubber $\left(A_{r}\right)$ and post-yielding stiffness are calculated using Eq. (19) and (20) respectively:

$\begin{aligned} A_{r} & =\frac{K_{D} t_{r}}{G}, \\ K_{p} & =\frac{G A_{r} f_{L}}{R_{T}},\end{aligned}$

where yield displacement $\left(u_{y}\right)$ is $0.05-0.1$ times of total rubber thickness $\left(R_{T}\right)$ based on experimental data; $f_{L}$ is a factor which commonly taken 1.5. The characteristic strength $(Q)$ of the elastomeric can be calculated using Eq. $(21)$. Then the yield force $\left(F_{y}\right)$ of the bearing can be calculated by Eq. (22):

$u_{y}=\frac{Q}{5.5 K_{p}}$,

$F y=Q+K_{p} u_{y}$.

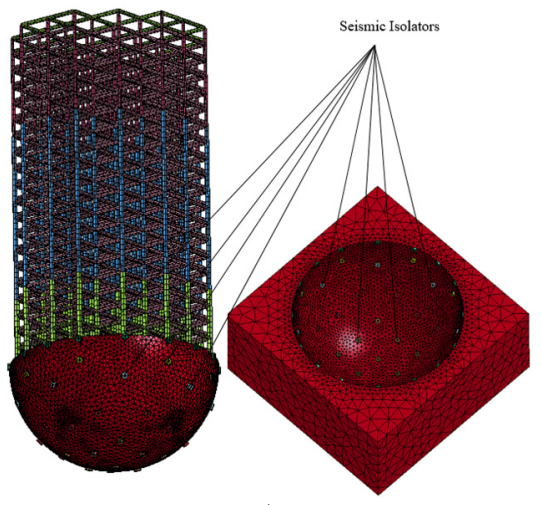

a)

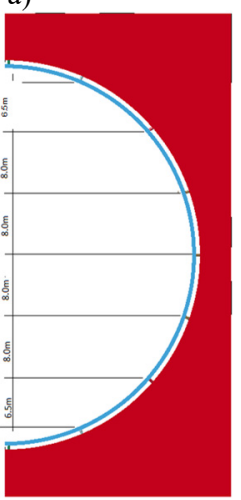

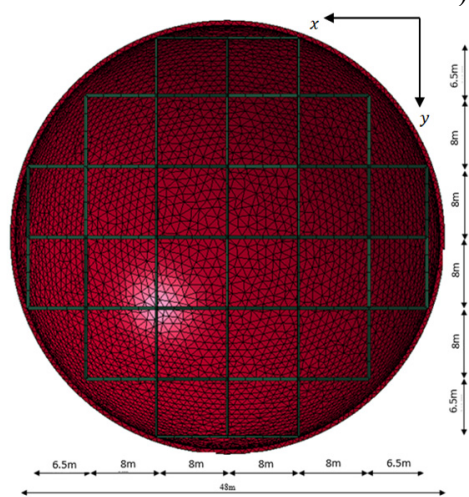

c)

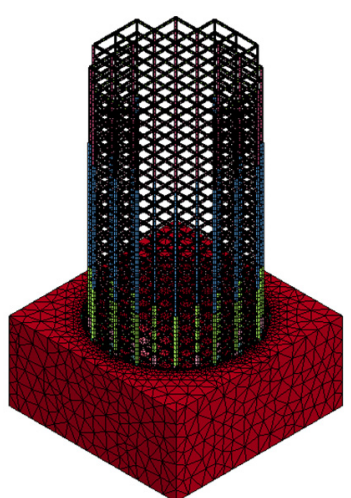

b) 
$E_{c}=\frac{6 G S^{2} K}{6 G S^{2}+K^{\prime}}$

where $E_{c}, G$ and $K$ is the compression of rubber-steel composite, shear and bulk modulus of rubber respectively. The value of $K$ and $G$ differs based on the type of rubber, the value of $K$ can vary between (1000 to $2500 \mathrm{MPa})$ and $G$ between $(0.45$ to $1 \mathrm{MPa})$. $S$ represents the hysteresis loop shape factor of the seismic isolator and the value of $S$ should range between 12 and 20. Based on the presented equation the parameters of the LCRB for SSIS-Bg and CAMSBID-Bg structures are calculated and presented in Table 4.

The final design of the elastomeric isolators parameters is implemented based on the compering first iteration results $K_{h, t o t a l}=53 \times 1.56 \mathrm{E}+6=82.68 \mathrm{E}+6 \mathrm{~N} / \mathrm{m}$ with the required total horizontal stiffness of the isolators $k_{b}=82.455 \mathrm{E}+6 \mathrm{~N} / \mathrm{m}$ obtained from Eq. (2). Then it can be confirmed in every iteration by the assessment of the hysteresis loop of the elastomeric isolator.

Table 4. Properties of seismic LCRB isolators for SSIS-Bg and CAMSBID-Bg structures

\begin{tabular}{|c|c|c|}
\hline Parameters & SSIS-Bg & CAMSBID-Bg \\
\hline$K_{v}$ (Vertical stiffness) $[\mathrm{N} / \mathrm{m}]$ & $2.2800 \mathrm{E}+09$ & $2.8330 \mathrm{E}+09$ \\
\hline$F_{y}$ (Yield force) $[\mathrm{N}]$ & $4.550 \mathrm{E}+05$ & $6.520 \mathrm{E}+05$ \\
\hline$K_{h}$ (Horizontal stiffness) $[\mathrm{N} / \mathrm{m}]$ & $1.560 \mathrm{E}+06$ & $2.230 \mathrm{E}+06$ \\
\hline Damping ratio $[\%]$ & $1.50 \mathrm{E}-01$ & $1.50 \mathrm{E}-01$ \\
\hline$u_{y}$ (Yield displacement) $[\mathrm{m}]$ & $4.50 \mathrm{E}-02$ & $4.50 \mathrm{E}-02$ \\
\hline$\phi$ (Diameter) $[\mathrm{m}]$ & $9.70 \mathrm{E}-01$ & $9.70 \mathrm{E}-01$ \\
\hline$R_{T}$ (Rubber thickness) $[\mathrm{m}]$ & $5.00 \mathrm{E}-01$ & $5.00 \mathrm{E}-01$ \\
\hline Number of isolators & 53 & 37 \\
\hline
\end{tabular}

\section{Numerical study}

Nonlinear dynamic analysis of the presented finite element model (Fig. 5) has been analysed using a total of five strong and long-period earthquakes, general characteristics of these earthquakes are presented in Table 5 and Fig. 6. Time-history data of the ground motions are obtained from PEER Berkeley Strong Ground Motion database [42]. The spectrum presented in Fig. 6 is used in the preliminary design of isolator in Section 2.1.
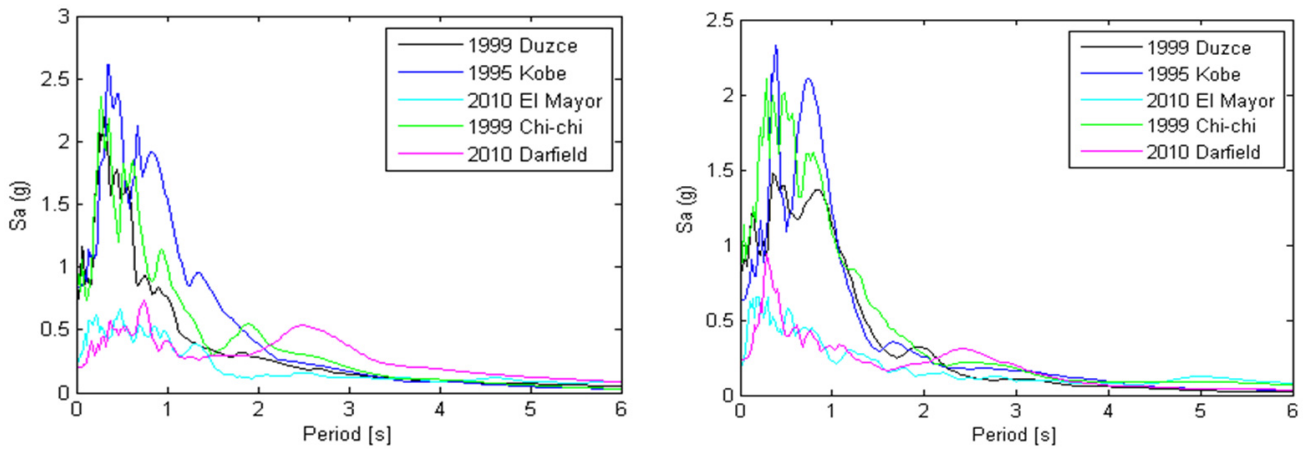

Fig. 6. The response spectra of the ground motions in $X$ and $Y$ direction respectively

Table 5. Ground motion characteristics

\begin{tabular}{|c|c|c|c|c|c|}
\hline Earthquake & Year & Station & PGA-X $[\mathrm{g}]$ & PGA-Y [g] & Type \\
\hline Duzce & 1999 & Bolu & 0.739 & 0.805 & Near fault \\
\hline Kobe & 1995 & KJMA & 0.833 & 0.628 & Near fault \\
\hline Elmayor & 2010 & Chihuahua & 0.248 & 0.196 & Far fault (long-period) \\
\hline Chi-Chi & 1999 & CHY028 & 0.636 & 0.760 & Near fault \\
\hline Darfield & 2010 & Cathedral College & 0.194 & 0.233 & Far fault (long-period) \\
\hline
\end{tabular}


The dynamic analyses of SSIS-Bg, CAMSBID-Bg and FB-Bg structures are conducted using LS-DYNA explicit solver [39], total CPU time for each analysis is approximately 10 hours and 40 minutes. Total of 12 CPU cores with 18 GBs of RAM is used during analyses. Base, top, base shear and base moment responses SSIS-Bg, CAMSBID-Bg and FB-Bg structures under effect of 1995 Kobe earthquake is provided in Fig. 7-11.
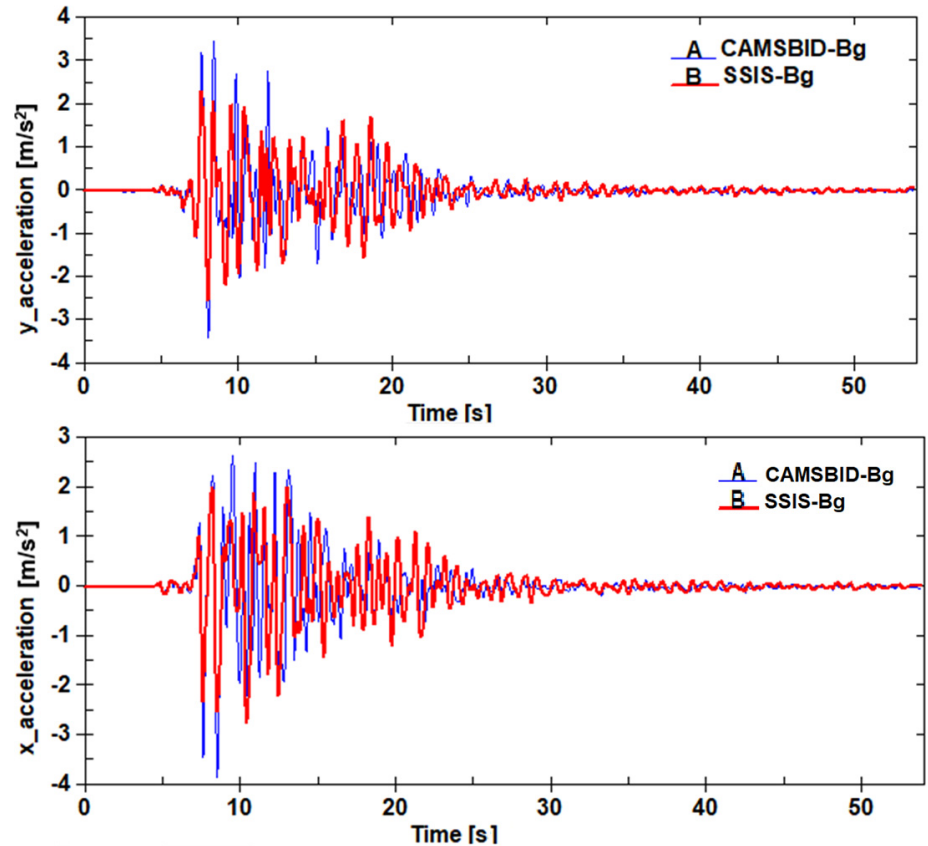

Fig. 7. Base acceleration responses of SSIS-Bg and CAMSBID-Bg structures in $X$ and $Y$ directions
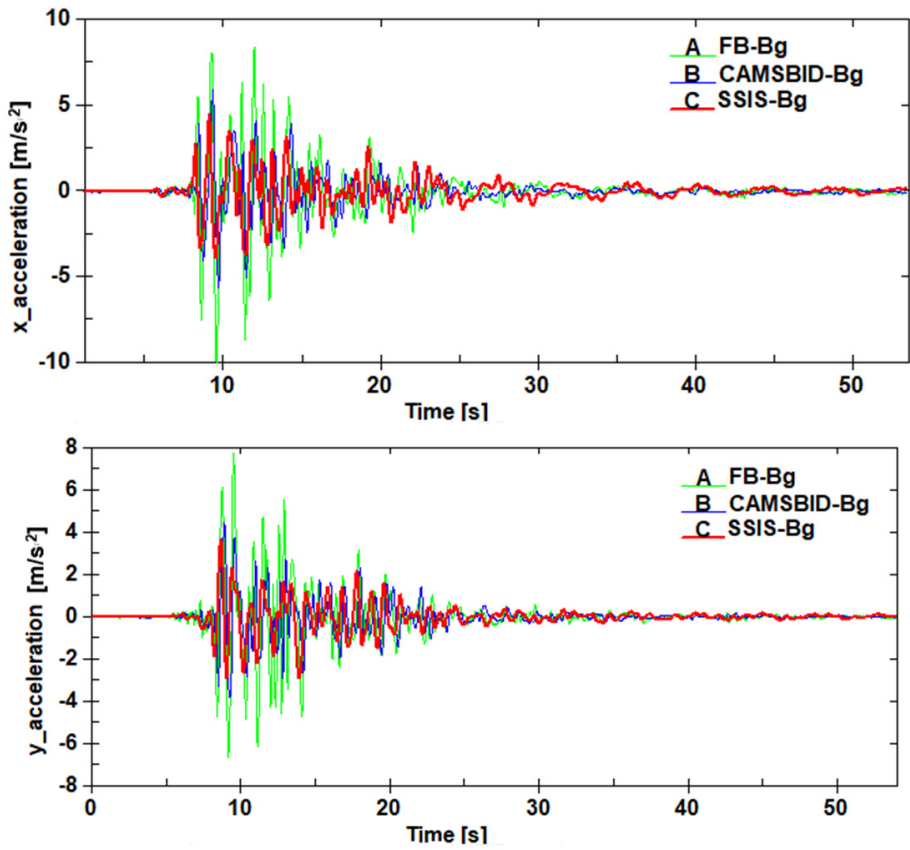

Fig. 8. Top storey acceleration responses of SSIS-Bg, CAMSBID-Bg and FB-Bg structures in $X$ and $Y$ directions 

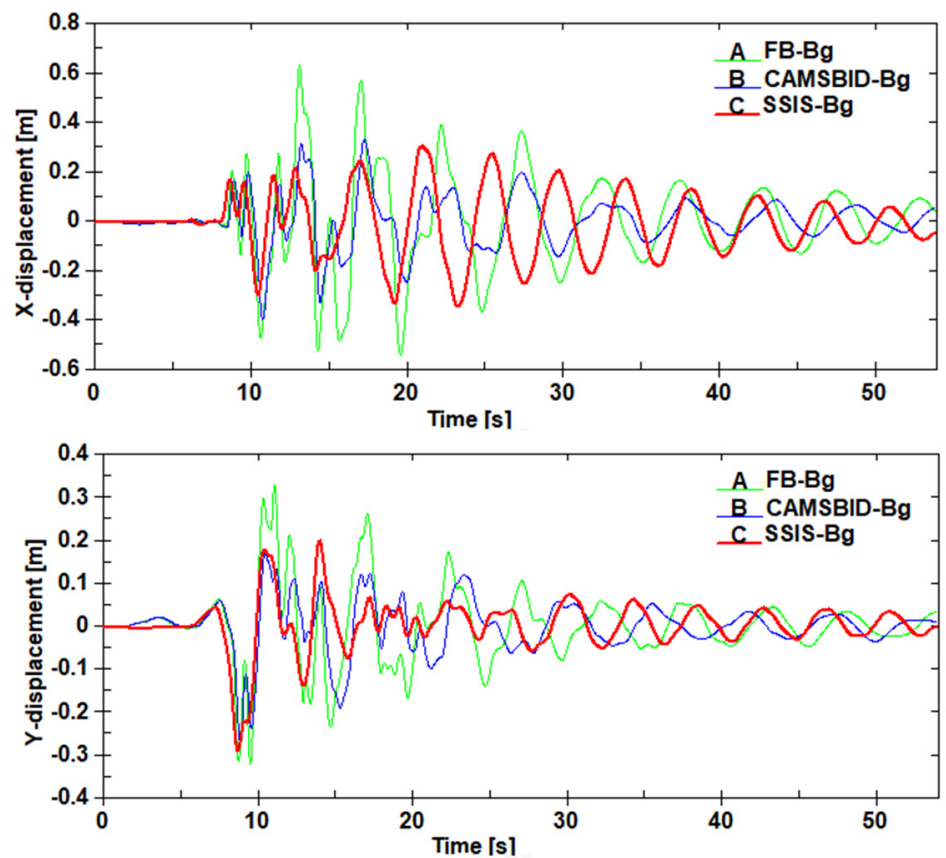

Fig. 9. Top storey displacement responses of SSIS-Bg, CAMSBID-Bg and FB-Bg structures in $X$ and $Y$ directions
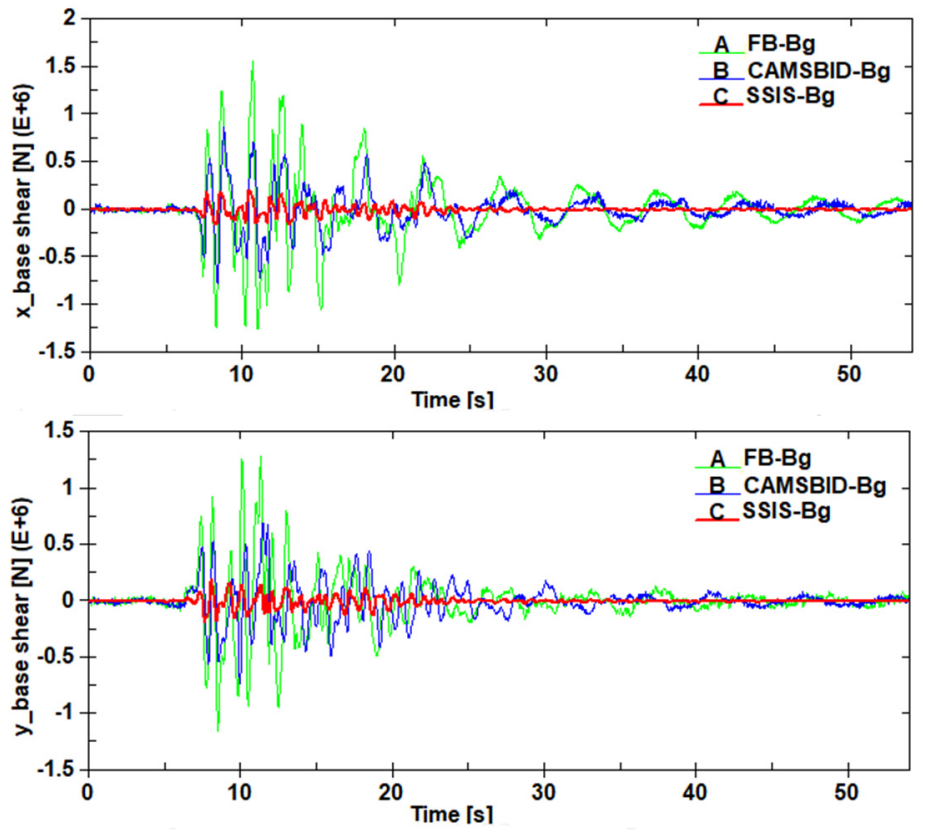

Fig. 10. Base shear response of SSIS-Bg, CAMSBID-Bg and FB-Bg structures in $X$ and $Y$ directions

\subsection{Results and discussion}

As presented in Figs. 7-8 the base and top acceleration response SSIS-Bg is tangibly lower than CAMSBID-Bg and FB-Bg structure in both $X$ and $Y$ directions. On the other hand, the top storey displacements of SSIS-Bg and CAMSBID-Bg are lower than FB-Bg structure and similar 
to each other as shown in Fig. 9.

While the acceleration response of SSIS-Bg is considerably lower than the CAMSBID-Bg and FB-Bg structures, the reduction of the base shear and base moment response of SSIS-Bg is significantly lower than CAMSBID-Bg and FB-Bg structures as well. It is achieved due to turn around the gyration centre of the SSIS-Bg structure. The base shear and base moment responses of SSIS-Bg, CAMSBID-Bg and FB-Bg structures due to the effect of the 1995 Kobe earthquake are presented in Fig. 10 and Fig. 11.
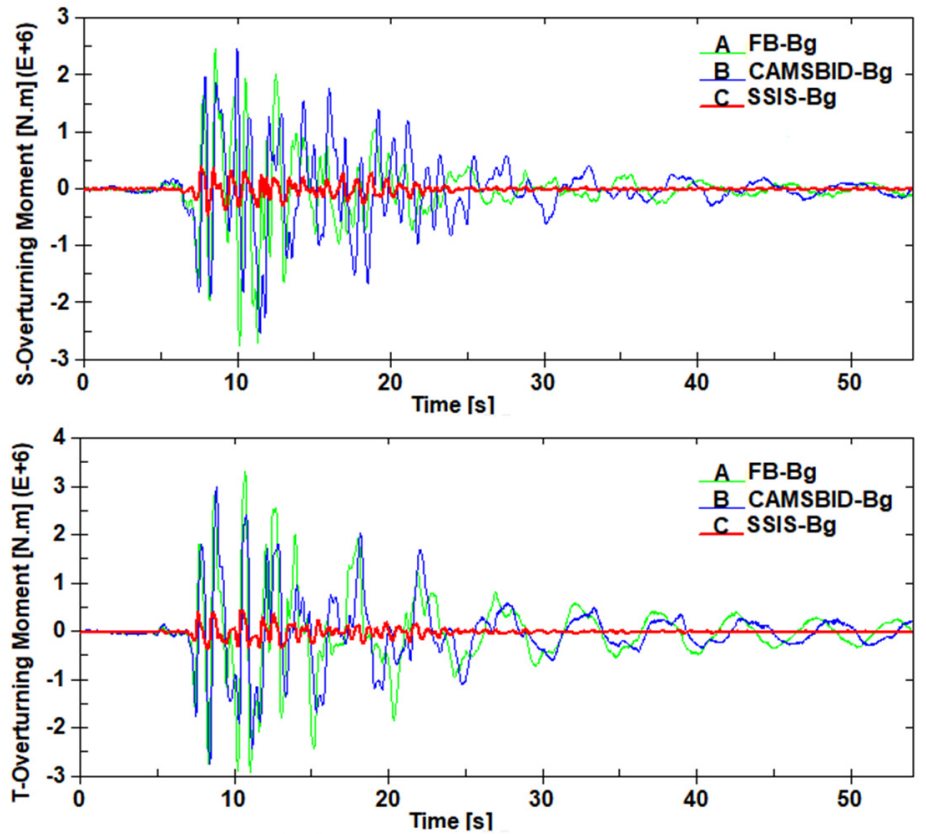

Fig. 11. Base moment response of SSIS-Bg, CAMSBID-Bg and FB-Bg structures in $X$ and $Y$ directions respectively

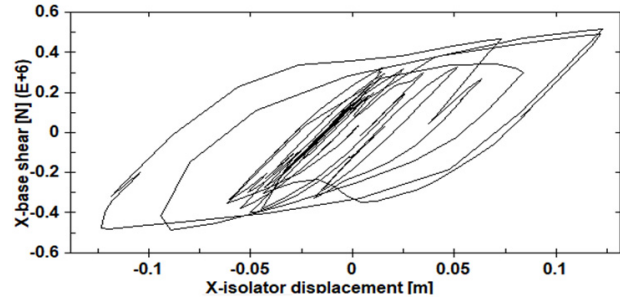

a)

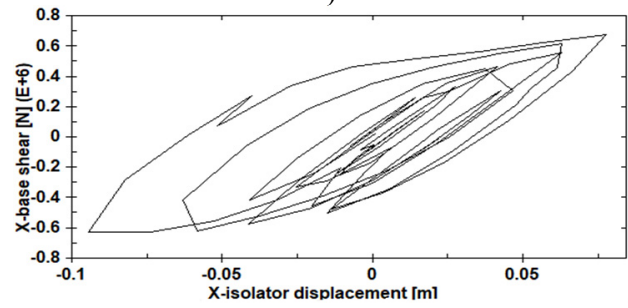

c)

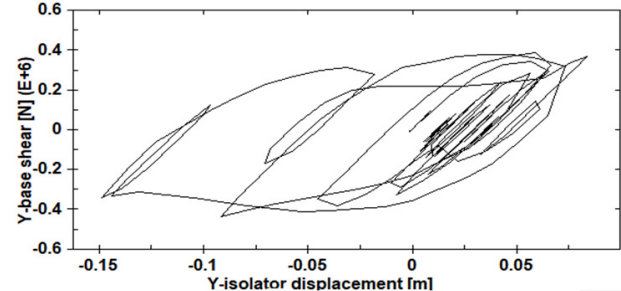

b)

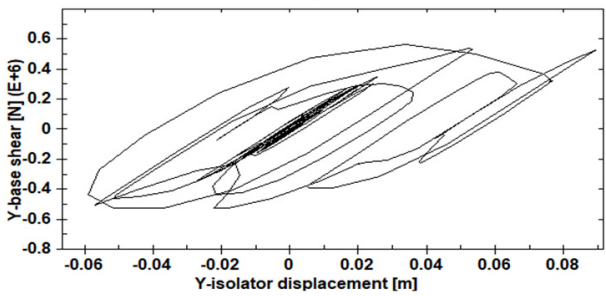

d)

Fig. 12. Comparison of the hysteresis loops of the central seismic isolator of a), b) SSIS-Bg, c) d) CAMSBID-Bg structures

All peak top acceleration, top displacement (Table 6), base shear and base moment responses 
(Table 7), base acceleration, base displacement (Table 8) of the SSIS-Bg, CAMSBID-Bg and FB-Bg structures are presented as follows.

The SSIS-Bg, CAMSBID-Bg and FB-Bg structures were analysed under the effect of strong and long-period earthquakes listed in Table 5. The base acceleration responses of the SSIS-Bg structure is $22.94 \%$ and $24.47 \%$ lower (on average) than the CAMSBID-Bg structure in $X$ and $Y$ directions respectively as shown in Fig 13 . Similarly, there are $19.21 \%$ and $26.22 \%$ difference between the top storey acceleration response of SSIS-Bg and CAMSBID-Bg structures as presented in Fig. 14. The response of FB-Bg structure clearly indicates to extreme vulnerably of similar structures under effect of long-period earthquakes.

Table 6. Top level acceleration and displacement peak responses of SSIS-Bg, CAMSBID-Bg and FB-Bg structures

\begin{tabular}{|c|c|c|c|c|c|c|c|c|c|c|c|c|}
\hline \multirow{3}{*}{$\begin{array}{l}\text { Ground } \\
\text { motions }\end{array}$} & \multicolumn{6}{|c|}{$X$-direction } & \multicolumn{6}{|c|}{$Y$-direction } \\
\hline & \multicolumn{3}{|c|}{ Top storey acc. $\left[\mathrm{m} / \mathrm{s}^{2}\right]$} & \multicolumn{3}{|c|}{ Top storey disp. [m] } & \multicolumn{3}{|c|}{ Top storey acc. $\left[\mathrm{m} / \mathrm{s}^{2}\right]$} & \multicolumn{3}{|c|}{ Top storey disp. [m] } \\
\hline & $\begin{array}{c}\text { SSIS- } \\
\text { Bg }\end{array}$ & $\begin{array}{c}\text { CAMSBID- } \\
\text { Bg }\end{array}$ & $\begin{array}{l}\text { FB- } \\
\text { Bg }\end{array}$ & $\begin{array}{c}\text { SSIS- } \\
\text { Bg }\end{array}$ & $\begin{array}{c}\text { CAMSBID- } \\
\text { Bg }\end{array}$ & $\begin{array}{c}\text { FB- } \\
\text { Bg }\end{array}$ & $\begin{array}{c}\text { SSIS- } \\
\text { Bg }\end{array}$ & $\begin{array}{c}\text { CAMSBID- } \\
\text { Bg }\end{array}$ & $\begin{array}{c}\text { FB- } \\
\text { Bg }\end{array}$ & $\begin{array}{c}\text { SSIS- } \\
\text { Bg }\end{array}$ & $\begin{array}{c}\text { CAMSBID- } \\
\text { Bg }\end{array}$ & $\begin{array}{c}\text { FB- } \\
\text { Bg }\end{array}$ \\
\hline Duzce & 3.63 & 4.28 & 7.68 & 0.563 & 0.625 & 0.721 & 3.51 & 4.64 & 6.59 & 0.238 & 0.231 & 0.245 \\
\hline Kobe & 4.621 & 6.25 & 12 & 0.31 & 0.212 & 0.414 & 3.11 & 4.25 & 7.89 & 0.28 & 0.27 & 0.351 \\
\hline Elmayor & 2.05 & 2.19 & 2.48 & 0.683 & 0.703 & 1.06 & 2.15 & 3.1 & 2.34 & 0.634 & 0.8032 & 1.027 \\
\hline Chi-Chi & 3.47 & 4.56 & 6.89 & 321 & 0.278 & 0.343 & 3.9 & 5.69 & 8.06 & 0.474 & 0.538 & 0.752 \\
\hline Darfield & 2.71 & 3.12 & 3.7 & 0.845 & 0.895 & 1.01 & 2.04 & 2.26 & 2.85 & 0.302 & 0.352 & 0.475 \\
\hline
\end{tabular}

Table 7. Base shear and base moment peak responses of SSIS-Bg, CAMSBID-Bg and FB-Bg structures

\begin{tabular}{|c|c|c|c|c|c|c|c|c|c|c|c|c|}
\hline \multirow{3}{*}{$\begin{array}{l}\text { Ground } \\
\text { motions }\end{array}$} & \multicolumn{6}{|c|}{$X$-direction } & \multicolumn{6}{|c|}{$Y$-direction } \\
\hline & \multicolumn{3}{|c|}{ Base shear $[\mathrm{N}] \times 10^{5}$} & \multicolumn{3}{|c|}{ Base mom. $[$ N.m] $] \times 10^{5}$} & \multicolumn{3}{|c|}{ Base shear $[\mathrm{N}] \times 10^{5}$} & \multicolumn{3}{|c|}{ Base mom. $[\mathrm{N} . \mathrm{m}] \times 10^{5}$} \\
\hline & $\begin{array}{c}\text { SSIS- } \\
\text { Bg }\end{array}$ & $\begin{array}{c}\text { CAMSBID- } \\
\text { Bg }\end{array}$ & \begin{tabular}{|c|} 
FB- \\
Bg
\end{tabular} & $\begin{array}{c}\text { SSIS- } \\
\text { Bg }\end{array}$ & $\begin{array}{c}\text { CAMSBID- } \\
\text { Bg }\end{array}$ & $\begin{array}{c}\text { FB- } \\
\mathrm{Bg}\end{array}$ & $\begin{array}{c}\text { SSIS- } \\
\mathrm{Bg}\end{array}$ & $\begin{array}{c}\text { CAMSBID- } \\
\text { Bg }\end{array}$ & $\begin{array}{c}\text { FB- } \\
\text { Bg }\end{array}$ & $\begin{array}{c}\text { SSIS- } \\
\mathrm{Bg}\end{array}$ & $\begin{array}{c}\text { CAMSBID- } \\
\text { Bg }\end{array}$ & $\begin{array}{c}\text { FB- } \\
\text { Bg }\end{array}$ \\
\hline Duzce & 1.87 & 6.67 & 10.0 & 5.31 & 19.3 & 31.5 & 2.36 & 5.54 & 9.11 & 4.18 & 28.9 & 36.6 \\
\hline Kobe & 2.1 & 7.86 & 15.21 & 4.56 & 24.87 & 27.5 & 2.28 & 7.96 & 12.25 & 3.53 & 30 & 33.3 \\
\hline Elmayor & 1.24 & 7.55 & 13.19 & 2.68 & 29.6 & 52.2 & 1.014 & 7.99 & 14.13 & 2.26 & 28.49 & 47.7 \\
\hline Chi-Chi & 2.67 & 6.15 & 8.22 & 4.41 & 32.6 & 47.6 & 1.97 & 8.89 & 13.2 & 6.00 & 21.14 & 35.3 \\
\hline Darfield & 1.178 & 7.81 & 10.3 & 2.03 & 19.6 & 25.1 & 0.918 & 5.34 & 6.76 & 2.56 & 29.3 & 40.38 \\
\hline
\end{tabular}

Table 8. Base level acceleration and displacement responses of SSIS-Bg, CAMSBID-Bg

\begin{tabular}{|c|c|c|c|c|c|c|c|c|}
\hline \multirow{2}{*}{$\begin{array}{c}\text { Ground } \\
\text { motions }\end{array}$} & \multicolumn{4}{|c|}{$X$-direction } & \multicolumn{4}{c|}{$Y$-direction } \\
\cline { 2 - 9 } & \multicolumn{2}{|c|}{ Base acc. [m/s $\left.{ }^{2}\right]$} & \multicolumn{2}{c|}{ Base disp. $[\mathrm{m}]$} & \multicolumn{2}{c|}{ Base acc. [m/s $\left.{ }^{2}\right]$} & \multicolumn{2}{c|}{ Base disp. [m] } \\
\cline { 2 - 9 } & SSIS-Bg & CAMSBID-Bg & SSIS-Bg & CAMSBID-Bg & SSIS-Bg & CAMSBID-Bg & SSIS-Bg & CAMSBID-Bg \\
\hline Duzce & 2.57 & 2.65 & 0.255 & 0.262 & 3.28 & 3.69 & 0.101 & 0.113 \\
\hline Kobe & 2.651 & 3.95 & 0.125 & 0.152 & 2.45 & 3.551 & 0.151 & 0.153 \\
\hline Elmayor & 1.49 & 1.58 & 0.39 & 0.405 & 1.46 & 1.47 & 0.316 & 0.422 \\
\hline Chi-Chi & 2.52 & 3.3 & 0.151 & 0.148 & 2.81 & 4.56 & 0.146 & 0.159 \\
\hline Darfield & 1.46 & 2.41 & 0.271 & 0.335 & 1.3 & 1.69 & 0.143 & 0.15 \\
\hline
\end{tabular}

While the acceleration response of SSIS-Bg structure is considerably lower compared to CAMSBID-Bg and FB-Bg structures, there is a tremendous difference between base shear and base moment responses of the SSIS-Bg, CAMSBID-Bg and FB-Bg structures. As presented in Fig. 15 the base shear response of SSIS-Bg structure is $74.86 \%$ and $76.08 \%$ lower (on average) than CAMSBID-Bg structure in $X$ and $Y$ directions respectively. On the other hand, the even higher differences are observed between the base moment response of SSIS-Bg and CAMSBID-Bg structures which is $84.92 \%$ and $86.55 \%$ in $X$ and $Y$ directions respectively (Fig. 16). 

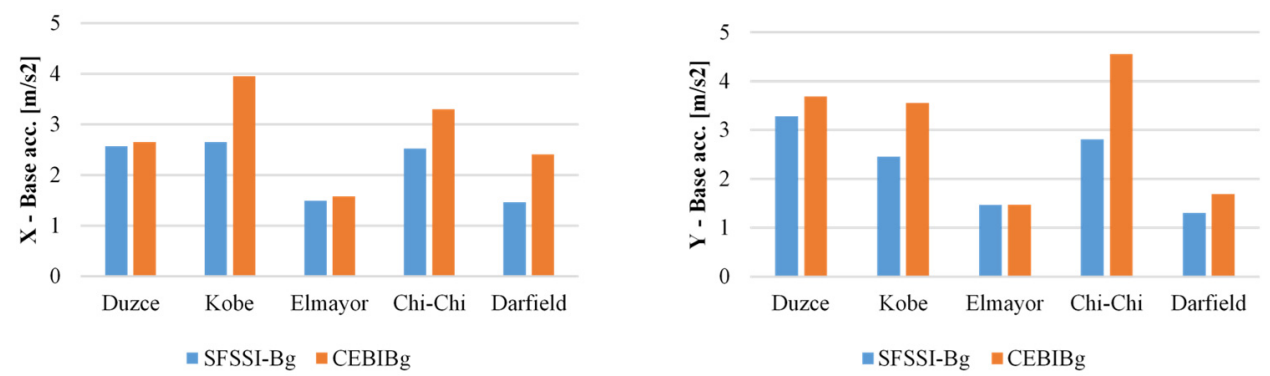

Fig. 13. Peak base acceleration response of SSIS-Bg, CAMSBID-Bg structures in $X$ and $Y$ directions
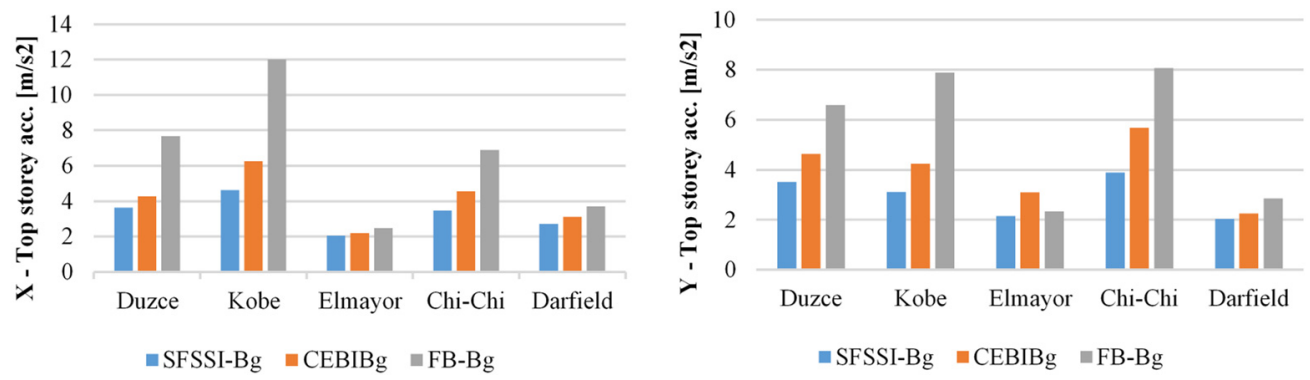

Fig. 14. Peak top storey acceleration responses of the SSIS-Bg, CAMSBID-Bg and FB-Bg structures in $X$ and $Y$ directions
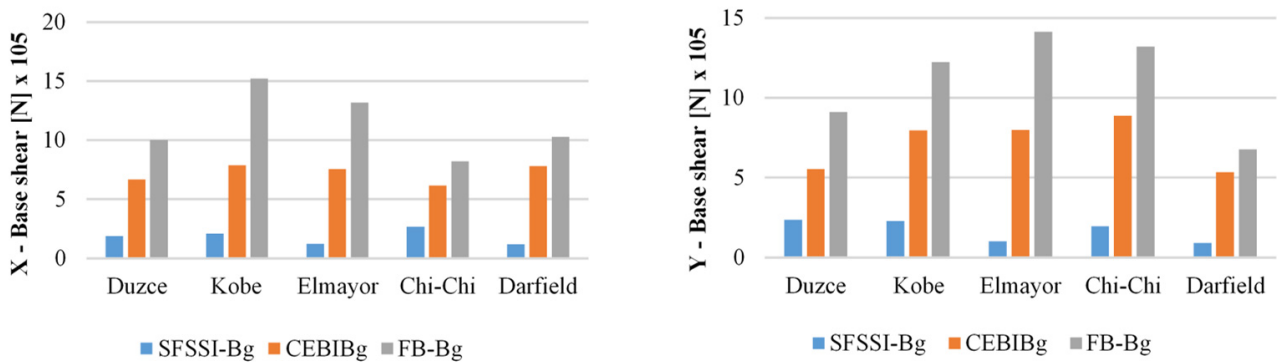

Fig. 15. Peak base shear response of the SSIS-Bg, CAMSBID-Bg and FB-Bg structures in $X$ and $Y$ directions
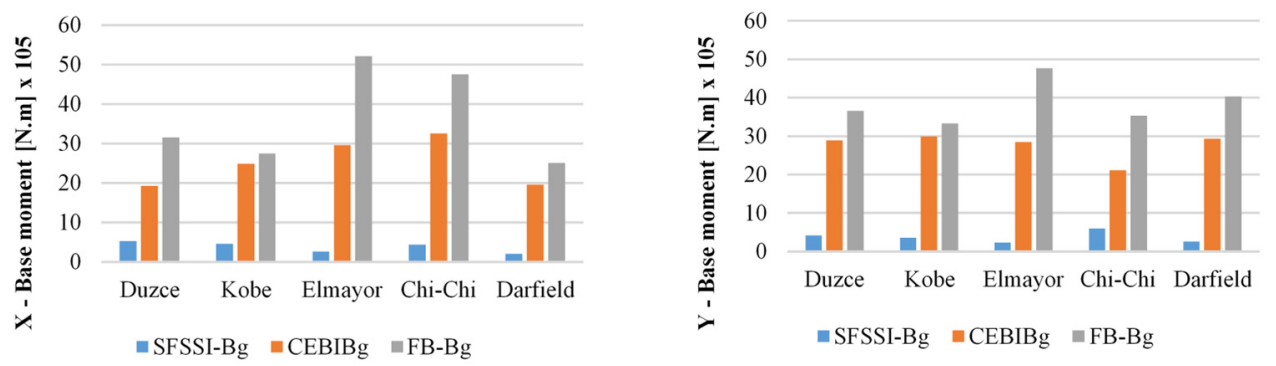

Fig. 16. Peak base moment responses of the SSIS-Bg, CAMSBID-Bg and FB-Bg structures in $X$ and $Y$ directions

\section{Conclusions}

The SSIS system obtained by the SSIM method for the seismic isolation of building structures (SSIS-Bg) has shown the following performances compared with the conventional application method of seismic base isolation devices for building (CAMSBID-Bg) structures and fixed base 
building structures (FB-Bg):

- Due to the reason that the SSIS system provides the opportunity of controlled rotation to the superstructure, less bending moment and shear forces were formed in the SSIS-Bg superstructure base, in comparison with CAMSBID-Bg structures. Mainly the base and top accelerations, base shear and base moment responses of the SSIS-Bg structure is $23.21 \%, 75.47 \%$ and $85.74 \%$ on average lower than CAMSBID-Bg structure respectively.

- The SSIS-Bg structure is not prone to resonant vibrations under long-period earthquakes related to the excessive deformation in the isolation layers.

- The significantly lower response of the SSIS-Bg structure compering with CAMSBID-Bg and FB-Bg structures allows to make it even lighter (in presented study approximately same total mass for SSIS-Bg, CAMSBID-Bg, FB-Bg structures was used only for comparability of the responses).

- Generally, in CAMSBID-Bg and FB-Bg high-rise buildings, approximately 1/3.1 -1/13.62 of the height of the superstructures mostly is considered a pile foundation. Hence, a considerable part of the structure cannot be used effectively. On the other hand, in CAMSBID-Bg system besides the feasibility of the usage of the underground part, all the mentioned system will be included in a curved surface foundation. Thus, in terms of total useful area of the buildings, the SSIS-Bg is much more efficient than CAMSBID-Bg and FB-Bg structures.

- SSIS system allows the efficient use of today's manufactured seismic protection devices (LRB, LCRB, etc.). As presented, structures with the conventional application of the seismic base isolation devices for Building (CAMSBID-Bg) are vulnerable under long-period earthquake excitation.

The feasibility of the usage of the SSIM method is not limited to high-rise buildings, it could be used as a seismic protection system for other important structures such as nuclear power plants, offshore oil platform, high-rise hospitals etc.

The feasibility of the usage structure foot base and foundation contact curved surfaces' types (spherical, elliptical, etc.) depending on the earthquake-soil-superstructure parameters, it is the subject of the futures research and is being studied.

Summarise, structural seismic protection SSIS system obtained by the presented SSIM method for highly reliable structures are very productive and attractive for applications and it closes certain known shortcomings of the conventional application of the seismic base isolation devices.

\section{Acknowledgements}

This research was supported by the Scientific and Technological Research Council of Turkey (TUBITAK). The support is gratefully acknowledged.

\section{References}

[1] Hall J. F., Heaton T. H., Halling M. W., Wald D. J. Near-source ground motion and its effects on flexible buildings. Earthquake Spectra, Vol. 11, Issue 4, 1995, p. 569-605.

[2] Loh C. H., Wu T. C., Huwang N. E. Application of the empirical mode decomposition - Hilbert spectrum method to identify near-fault ground-motion characteristics. Bulletin of the Seismological Society of America, Vol. 9, Issue 5, 2001, p. 1339-1357.

[3] Baker J. W. Quantitative classification of near-fault ground motions using wavelet analysis. Bulletin of the Seismological Society of America, Vol. 97, Issue 5, 2007, p. 1486-1501.

[4] Tanaka T., Yoshizawa S., Osawa Y. Characteristics of strong earthquake ground motion in the period range from 1 to 15 seconds: analysis of low magnification seismograph records. Bulletin of Earthquake Research Institute, Vol. 54, Issue 3, 1979.

[5] Jangid R. S., Kelly J. M. Base isolation for near-fault motions. Earthquake Engineering and Structural Dynamics, Vol. 30, Issue 5, 2001, p. 691-707.

[6] Earthquakes and Tsunamis. Japan Meteorological Agency, Otemachi, Chiyoda-ku, Tokyo, Japan, 2018, https://www.jma.go.jp/jma/kishou/books/jishintsunami/en/jishintsunami_en.pdf. 
[7] Kazuki K., Hiroe M. A seismological overview of long-period ground motion. Journal of Seismology, Vol. 12, Issue 2, 2008, p. 133-143.

[8] Higashino M., Okamoto S. Response Control and Seismic Isolation of Buildings. Taylor and Francis, London, 2006.

[9] Naeim F., Kelly J. M. Design of Seismic Isolated Structures: from Theory to Practice. John Wiley and Sons, New York, 1999.

[10] Jangid R. S. Optimum friction pendulum system for near-fault motions. Engineering Structures, Vol. 27, Issue 4, 2005, p. 349-359.

[11] Saito T. Behavior of response controlled and seismically isolated buildings during severe earthquakes in Japan. Energia Ambiente e Innovazione, Vol. 61, Issue 5, 2015, p. 31-37.

[12] Lu L. Y., Lin G. L., Kuoa T. C. Stiffness controllable isolation system for near-fault seismic isolation. Engineering Structures, Vol. 30, Issue 3, 2008, p. 747-766.

[13] Hosseini M., Soroor A. Using orthogonal pairs of rollers on concave beds (OPRCB) as a base isolation system - part II: application to multi-story and tall buildings. The Structural Design of Tall and Special Buildings, Vol. 22, Issue 8, 2013, p. 192-117.

[14] Ismail M., Rodellar J., Ikhouane F. Performance of structure-equipment systems with a novel rolln-cage isolation bearing. Computers and Structures, Vol. 87, Issues 23-24, 2009, p. 1631-146.

[15] Herbut A. A proposal for vibration isolation of structures by using a wave generator. Soil Dynamics and Earthquake Engineering, Vol. 100, 2017, p. 573-585.

[16] Fabio M., Mirko M., Alfonso V. Base-isolation systems for the seismic retrofitting of r.c. framed buildings with soft-storey subjected to near-fault earthquakes. Soil Dynamics and Earthquake Engineering, Vol. 109, 2018, p. 209-221.

[17] Kasimzade A. A., Tachibana E., Mukai Y., Tuhta S., Atmaca G. Spherical foundation base isolation system on base ancient architecture inherence. International Symposium on Disaster Simulation, Japan, 2015, p. 127-133.

[18] Kasimzade A. A., Tachibana E., Mukai Y., Tuhta S., Atmaca G. Spherical foundation structural seismic isolation system: development of the new type earthquake resistant structures. 6th International Conference on Theoretical and Applied Mechanics, Italy, 2015, p. 287-292.

[19] Kasimzade A. A., Şafak E., Ventura C. E., Naeim F., Mukai Y. Seismic Isolation, Structural Health Monitoring, and Performance-Based Seismic Design in Earthquake Engineering: Recent Developments. Springer, 2018.

[20] Kasimzade A. A., Onbilgin G., Atmaca G., Tuhta S. Structural Seismic Isolation System-SSIS. Turkey Patent TR2019/20153, 2019.

[21] Kasimzade A. A., Abrar O., Tuhta S., Atmaca G. Investigation of Seismic Base Isolated Structures for Long Period Ground Motions. International Journal of Engineering and Applied Sciences, Vol. 5, Issue 6, 2018, p. 812-818.

[22] Wu C. Anti-Earthquake Structure Insulating the Kinetic Energy of Earthquake from Buildings. U.S. Patent, US4881350A, 1988.

[23] Yoneda R. Earthquake-Proof Object Support Devices. U.S. Patent, US5979127A, 1996.

[24] Lee W. L. Rocking-Type Seismic Isolation Base for Protecting Structure Against Earthquake. U.S. Patent, US20060260222A1, 2006.

[25] Huber P., Roos R. Friction Pendulum Bearing. U.S. Patent, US20090188179A1, 2006.

[26] Quaglini V., Cuminetti D., Dubini P., Motta R., Ferroni D. Antiseismic Support. U.S. Patent, US20140026498A1, 2012.

[27] Yu S., Yi H. Earthquake -Resistant Structure. China Patent Office, CN205077505U, 2015.

[28] Junyong X., Hui G., Xia B., Louliang N. Double Sphere Friction Simple Pendulum Support. China Patent Office, CN205152779U, 2015.

[29] Meguire J., Porter M. Spheroidial Joint for Column Support in a Tuned Mass Damper System. U.S. Patent, US20170108034A1, 2016.

[30] Chunming S., Zhengjun Q. Assembling Type Building Earthquake-Proof Foundation and Building. China Patent Office, CN106930311A, 2017.

[31] Shimoda I., Suzuki K. Base Isolation Supporting Device. U.S. Patent, US20170342734A1, 2014.

[32] Yu W., Zhijun W. Circle-Egg Thin-Shell Frame Shake-Type Earthquake-Wave-Resistant Architectural Structure. China Patent Office, CN107514175A, 2017.

[33] Yu W., Zhijun W. Ovum Circle Shell Frame Shaking Type Ripples Building Structure of Antiseismic. China Patent Office, CN207228740U, 2017. 
[34] Massa L., Marenda I. Sliding Bearing for Supporting Civil or Structural Engineering Works. U.S. Patent, US20180195267A1, 2016.

[35] Kasimzade A. A. Finite Element Method: Foundation and Application to Earthquake Engineering (including educational finite element analysis software CD-MATLAB codes). Nobel Publication, Istanbul, Turkey, 2018.

[36] Ikhouane F., Rodellar J. Systems with Hysteresis: Analysis, Identification and Control using the Bouc - Wen Model. Wiley, 2007.

[37] Wen Y. K. Method for random vibration of hysteretic systems. Journal of Engineering Mechanics, Vol. 102, Issue 2, 1976, p. 249-264.

[38] LSTC. LS-DYNA Keywords User Manual Vol. 1. Livermore Sofware Technology Corporation, California, USA, 2013.

[39] ASCE 7-16. Minimum Design Loads for Buildings and Other Structures. American Society of Civil Engineers, Reston, 2016.

[40] ASCE 41-13. Seismic Evaluation and Retrofit of Existing Buildings. American Society of Civil Engineers, Reston, 2013.

[41] PEER. PEER Strong Ground Motion Database, Berkeley University, 2018. https://ngawest2.berkeley.edu/.

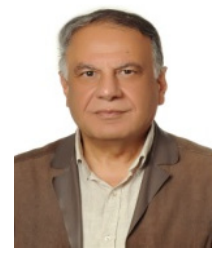

Azer Arastunoglu Kasimzade received his Ph.D. and Doctor of Sciences (D.Sc.) degrees in structural mechanics from Moscow Civil Engineering University respectively in 1983 and 1991. In 1992 he was a Professor at the Civil Engineering University. Since 1995 he is a Professor and head of Structural Mechanics Division at the Ondokuz Mayis University, Turkey. He is a member of several national and international professional societies and advisory committees, the author of monographs, books, papers, reports and directed many projects related with seismic isolation, system identification and earthquake engineering problems of civil engineering structures.

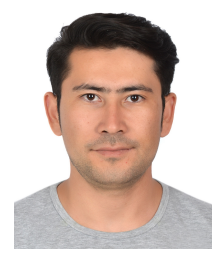

Obaidullah Abrar received his M.Sc. degree in civil engineering from Ondokuz Mayis University, Turkey, in 2018. Now he is a Ph.D. student of the Civil Engineering Department Ondokuz Mayis University. His current research interests include passive seismic control of structures.

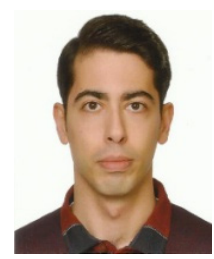

Gencay Atmaca received his M.Sc. degree in civil engineering from Ondokuz Mayis University, Turkey, in 2012 and 2020 years respectively. Now he works at Provincial Directorate of Disaster and Emergency, Samsun, Turkey. His current research interests include finite element method, structural dynamics and seismic isolation.

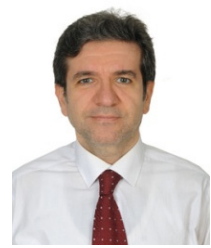

Mehmet Kuruoglu received Ph.D. degree in civil engineering from Dokuz Eylul University, Izmir, Turkey, in 2004. Now he works at Dokuz Eylul University as an Assistant Professor. His current research interests include soil dynamics and geotechnical earthquake engineering. 